\title{
The Efficacy of Chemotherapy in Survival of Esophageal Cancer With Bone Metastasis: A Propensity Score-Matched Analysis of The SEER Database
}

\section{junyuan chen}

First Affiliated Hospital of Jinan University

Jieruo Li

First Affiliated Hospital of Jinan University

\section{Tsz-Ngai Mok}

First Affiliated Hospital of Jinan University

Jiaquan Zhong

University of Hong Kong - Shenzhen Hospital

\section{Guorong She}

First Affiliated Hospital of Jinan University

\section{Huajun Wang}

First Affiliated Hospital of Jinan University

\section{Qiushi Wang}

First Affiliated Hospital of Jinan University

\section{Songwei Huan}

First Affiliated Hospital of Jinan University

\section{Zhengang Zha}

First Affiliated Hospital of Jinan University

\section{Simin Luo}

First Affiliated Hospital of Jinan University

\section{Ning Liu ( $0385327952 @ q q . c o m$ )}

First Affiliated Hospital of Jinan University

\section{Research Article}

Keywords: esophageal cancer, bone metastasis, chemotherapy, prognosis, SEER

Posted Date: August 26th, 2021

DOl: https://doi.org/10.21203/rs.3.rs-821003/v1 
License: (1) This work is licensed under a Creative Commons Attribution 4.0 International License. Read Full License 


\section{Abstract \\ Background}

The esophageal cancer patients with bone metastasis present with an extremely poor prognosis. The aim of this study was to establish a comprehensive insight into whether chemotherapy is justifiably being prescribed to esophageal cancer patients with bone metastasis.

\section{Methods}

A population-based retrospective study was conducted with data from the Surveillance, Epidemiology, and End Results (SEER) national database. By performing 1:1 paired match propensity score matching (PSM), we minimized the baseline discrepancies between groups. Univariate and multivariate Cox regression analyses were used to identify factors associated with survival. Kaplan-Meier survival curves were used to assess the effects of chemotherapy on survival.

\section{Results}

The final PSM cohort consisted of 730 patients, including 365 patients in the chemotherapy group and 365 patients in the non-chemotherapy group. There was a significant difference in overall survival $(O S, p<0.001)$ and cancer-specific survival (CSS, $p<0.001)$ between the two groups. The median OS time for the chemotherapy group was 9.8 (95\% Cl: 8.5-11.2) months, and it was decreased to $2.3(95 \% \mathrm{Cl} 1.9-2.7)$ months in the non-chemotherapy group. Multivariate analysis confirmed that chemotherapy was an independent prognostic factor for OS $(p<0.001)$ and CSS $(p<0.001)$. Kaplan-Meier survival analysis suggested that chemotherapy could significantly improve OS $(p<0.001)$ and CSS $(p<0.001)$ both in squamous cell carcinoma or adenocarcinoma subgroup. However, there was no significant difference in both OS $(p=0.291)$ and CSS ( $p$ $=0.651)$ between the two groups for stage $\Downarrow$ esophageal carcinoma.

\section{Conclusion}

Chemotherapy significantly improved OS and CSS in esophageal cancer patients with bone metastasis. However, chemotherapy might not improve the prognosis of grade I esophageal cancer.

\section{Introduction}

Esophageal cancer is the sixth common cause of cancer-related death cancer that approximately 17,650 esophageal cancer cases were diagnosed in the United States in 2019. ${ }^{1-3}$ In Europe, morbidity increased by $39.6 \%$ for male and $37.5 \%$ for female in the last 10 years. ${ }^{4,5}$ Bone is one of the most common metastasis sites of esophageal cancer, and it often accompanies severe skeletal-related events, such as pathological fracture, spinal cord compression and hypercalcemia, which can lead to a catastrophic physical function and quality of life $^{6-8}$. Moreover, associating with bone metastasis, the esophageal cancer patients present with an extremely 
poor prognosis, with a less than $5 \%$ five-year survival rate ${ }^{6,9}$. Esophageal cancer with bone metastasis increases the burden of the health system and economic system across the world. ${ }^{10}$ Therefore, the management of esophageal cancer with bone metastasis is a crucial issue for patients and physicians.

To improve the quality of life and prognosis is the ultimate goal for end-stage cancer, especially with bone metastasis. Chemotherapy administration is one of the standard treatments for esophageal cancer patients with distant organ metastases $7,8,11$. According to National Comprehensive Cancer Network (NCCN) guidelines, palliative management, which includes concurrent chemoradiation or chemotherapy, is recommended for esophageal cancer patients with unresectable locally advanced or metastatic disease ${ }^{12}$.

Several retrospective studies also elucidate that chemotherapy may ameliorate the prognosis for the esophageal cancer patients ${ }^{11,13,14}$, but there is limited literature about chemotherapy for esophageal cancer with distant bone metastasis. YOSHINORI et al. found that receipt of chemotherapy following bone metastasis were significantly associated with overall survival in esophageal cancer ${ }^{8}$. Moreover, as the toxicity and the treatment-related adverse event of chemotherapy, it is not clear if all esophageal cancer with bone metastasis may obtain a survival and prognosis benefit from chemotherapy.

The identification of the beneficial factors of the chemotherapy aids the physicians to manage the palliative plan more efficiently for the esophageal cancer patients with bone metastasis. This study aims to establish a comprehensive insight into whether chemotherapy is justifiably prescribed to esophageal cancer patients with bone metastasis based on the Surveillance, Epidemiology, and End Results (SEER) database.

\section{Materials And Methods}

\section{Study population and data sources}

A population-based retrospective study was conducted with data from the SEER database. The SEER database has collected data on cancer incidence and relative survival since 1973 , which covered about $28 \%$ of the US population (https://seer.cancer.gov/). The present analysis includes data from the SEER 18 registries.

This study was based on a publicly SEER database and a data use agreement was assigned. This study was deemed exempt by the ethics committee of the First Affiliated Hospital of Jinan University. The requirement for informed consent was waived by the ethics committee of the First Affiliated Hospital of Jinan University. All methods were performed in accordance with relevant guidelines and regulations.

\section{Case ascertainment}

Data were retrieved through online access using the SEER ${ }^{*}$ Stat software version 8.38. The site codes C15.0C15.5, C15.8 and C15.9 were used to identify primary esophageal cancer. A total of 24,134 cases of esophageal carcinoma were extracted in the SEER database from 2010 to 2015. Patients were excluded for the following reasons: (1) cases with no bone metastasis or unknown; (2) not first primary malignancy; (3) cases with unknown marital status, grade, AJCC N stage or survival time; (4) cases diagnosis by autopsy and death certificate (Fig. 1). The included patients were classified into the chemotherapy group and the nonchemotherapy group. 


\section{Propensity score matching (PSM)}

PSM is a superior and refined statistical method of adjusting for potential baseline confounding factors. To reduce bias from confounding factors between groups, a 1:1 paired match PSM was performed. Matching covariates consisted of age, sex, race, marital status, histology and radiotherapy. The final cohort consisted of 365 patients in chemotherapy group and 365 patients in non-chemotherapy group.

\section{Statistical analysis}

The frequency and proportion of the baseline characteristics in the study cohort were described by Chi-square test. Kaplan-Meier survival curves were plotted to estimate the Overall survival (OS) and cancer-specific survival (CSS). Log-rank test was applied in comparing survival. Univariate analysis was performed with variables including age, marital status, primary site, grade, histology, $\mathrm{N}$ stage, metastasis status and therapy. The variables which were statistically meaningful $(p<0.05)$ or were considered clinically worth exploring were taken into the multivariate Cox regression analyses to determine the independent prognostic factors of esophageal cancer patients with bone metastasis. PSM was carried out as described above. A two-tailed $p<$ 0.05 was considered statistically significant. All statistical analyses were performed using SPSS 24.0 (IBM Corporation, Armonk, NY, USA).

\section{Results}

\section{Population characteristics}

From the SEER database, we finally identified 924 esophageal carcinoma patients with bone metastasis from 2010 to 2015. Before PSM, the Chi-squared test results showed that significantly differences between the two groups were observed for age $(p=0.017)$, marital status $(p<0.001)$, histology $(p=0.001)$ and radiotherapy $(p<$ 0.001). To reduce the imbalance and impacts of the baseline characteristics between groups, a 1:1 paired match PSM was performed. After PSM, all of the baseline characteristics except radiotherapy $(p<0.001)$ were no statistically significant differences $(p>0.05)$ between the two groups. The final PSM cohort consisted of 730 patients, including 365 patients in the chemotherapy group and 365 patients in the non-chemotherapy group. Baseline patient characteristics before and after PSM are summarized in Table 1. 
Table 1

Demographics and clinicopathological characteristics in esophageal cancer patients.

\begin{tabular}{|c|c|c|c|c|c|c|}
\hline \multirow[t]{2}{*}{ Variables } & \multicolumn{3}{|c|}{ Data before PSM } & \multicolumn{3}{|l|}{ Data after PSM } \\
\hline & $\begin{array}{l}\text { Chemotherapy } \\
\text { (\%) }\end{array}$ & $\begin{array}{l}\text { Non- } \\
\text { chemotherapy } \\
\text { (\%) }\end{array}$ & $\begin{array}{l}p \\
\text { value }\end{array}$ & $\begin{array}{l}\text { Chemotherapy } \\
\text { (\%) }\end{array}$ & $\begin{array}{l}\text { Non- } \\
\text { chemotherapy } \\
\text { (\%) }\end{array}$ & $\begin{array}{l}p \\
\text { value }\end{array}$ \\
\hline Age & & & 0.017 & & & 0.541 \\
\hline$\leq 60$ years & 249 & 133 & & 141 & 133 & \\
\hline$>60$ years & 310 & 232 & & 224 & 232 & \\
\hline Sex & & & 0.302 & & & 0.658 \\
\hline Male & 497 & 316 & & 320 & 316 & \\
\hline Female & 62 & 49 & & 45 & 49 & \\
\hline Race & & & 0.178 & & & 0.301 \\
\hline White & 484 & 306 & & 300 & 306 & \\
\hline Black & 42 & 42 & & 36 & 42 & \\
\hline Al & 27 & 13 & & 22 & 13 & \\
\hline API & 7 & 4 & & 7 & 4 & \\
\hline $\begin{array}{l}\text { Marital } \\
\text { status }\end{array}$ & & & $\begin{array}{l}< \\
0.001\end{array}$ & & & 0.116 \\
\hline Married & 367 & 177 & & 204 & 177 & \\
\hline Single & 88 & 85 & & 68 & 85 & \\
\hline DSW & 104 & 103 & & 93 & 103 & \\
\hline Primary site & & & 0.098 & & & 0.435 \\
\hline upper third & 18 & 16 & & 16 & 16 & \\
\hline middle third & 103 & 69 & & 68 & 69 & \\
\hline lower third & 360 & 210 & & 227 & 210 & \\
\hline overlapping & 78 & 70 & & 54 & 70 & \\
\hline Grade & & & 0.107 & & & 0.436 \\
\hline I & 20 & 10 & & 14 & 10 & \\
\hline II & 195 & 102 & & 113 & 102 & \\
\hline III & 329 & 244 & & 225 & 244 & \\
\hline
\end{tabular}

Al: American Indian/Alaska Native; API: Asian or Pacific Islander; DSW: divorced, separated and widowed; ESCC, esophageal squamous cell carcinoma; EAC, esophageal adenocarcinoma. 


\begin{tabular}{|c|c|c|c|c|c|c|}
\hline \multirow[t]{2}{*}{ Variables } & \multicolumn{3}{|c|}{ Data before PSM } & \multicolumn{3}{|l|}{ Data after PSM } \\
\hline & $\begin{array}{l}\text { Chemotherapy } \\
\text { (\%) }\end{array}$ & $\begin{array}{l}\text { Non- } \\
\text { chemotherapy } \\
\text { (\%) }\end{array}$ & $\underset{\text { value }}{p}$ & $\begin{array}{l}\text { Chemotherapy } \\
\text { (\%) }\end{array}$ & $\begin{array}{l}\text { Non- } \\
\text { chemotherapy } \\
\text { (\%) }\end{array}$ & $\begin{array}{l}p \\
\text { value }\end{array}$ \\
\hline IV & 15 & 9 & & 13 & 9 & \\
\hline Histology & & & 0.001 & & & 0.811 \\
\hline ESCC & 108 & 96 & & 92 & 96 & \\
\hline EAC & 412 & 226 & & 234 & 226 & \\
\hline Others & 39 & 43 & & 39 & 43 & \\
\hline $\mathrm{N}$ stage & & & 0.366 & & & 0.571 \\
\hline NO & 133 & 102 & & 87 & 102 & \\
\hline N1 & 332 & 211 & & 221 & 211 & \\
\hline N2 & 59 & 29 & & 35 & 29 & \\
\hline N3 & 35 & 23 & & 22 & 23 & \\
\hline Radiotherapy & & & $\begin{array}{l}< \\
0.001\end{array}$ & & & $\dot{0} 001$ \\
\hline Done & 334 & 152 & & 268 & 152 & \\
\hline None & 225 & 213 & & 97 & 213 & \\
\hline Surgery & & & 0.773 & & & 1 \\
\hline Done & 8 & 4 & & 4 & 4 & \\
\hline None & 551 & 361 & & 361 & 361 & \\
\hline
\end{tabular}

\section{Survival analysis}

Kaplan-Meier survival analysis was used to evaluate the OS and CSS of the chemotherapy and nonchemotherapy groups. As shown in Fig. 2 , there was statistical difference in OS $(p<0.001)$ and CSS $(p<0.001)$ between the two groups, indicated that chemotherapy could significantly improve OS and CSS. The median OS time for the chemotherapy group was 9.8 (95\% Cl: 8.5-11.2) months, and it was decreased to $2.3(95 \% \mathrm{Cl} 1.9-$ 2.7) months in the non-chemotherapy group.

In addition, the subgroup survival analysis among different histological subtypes and grades were conducted to explore the different effects of these factors on the chemotherapy group and non-chemotherapy group. Kaplan-Meier survival analysis suggested that no matter in squamous cell carcinoma or adenocarcinoma subgroups, chemotherapy could significantly improve OS ( $p<0.001$, Fig. 3A, B) and CSS $(p<0.001$, Fig. 3C, D), 
chemotherapy was a good prognostic indicator for OS and CSS for both squamous cell carcinoma and adenocarcinoma patients.

The chemotherapy group had a better OS ( $p<0.001$, Fig. 4B-D) and CSS $(p<0.001$, Fig. 4F-H) than the nonchemotherapy group in patients with stage $\triangle-\otimes$ esophageal carcinoma. However, there was no significant difference in both OS ( $p=0.291$, Fig. 4A) and CSS ( $p=0.651$, Fig. 4E) between the chemotherapy and nonchemotherapy groups for stage $₫$ esophageal carcinoma patients.

\section{Univariate and multivariate Cox regression}

Univariate and multivariate Cox regression analysis were performed to further assess the impact of chemotherapy on the prognosis of esophageal carcinoma patients with bone metastasis. Univariate analysis showed that marital status, histology, chemotherapy, radiotherapy, surgery, brain metastasis and lung metastasis were associated with OS (all $p<0.05$, Table 2 ) and CSS (all $p<0.05$, Table 3 ). Then we performed multivariate analysis on variables that were statistically or clinically meaningful in univariate analysis. 
Table 2

Univariate and multivariable Cox regression of OS for analyzing the prognosis factors for primary esophageal cancer with bone metastases

\begin{tabular}{|c|c|c|c|c|c|c|}
\hline \multirow[t]{2}{*}{ Variables } & \multicolumn{3}{|c|}{ Univariate analysis } & \multicolumn{3}{|c|}{ Multivariate analysis } \\
\hline & Hazard ratio & $95 \% \mathrm{Cl}$ & $p$ value & Hazard ratio & $95 \% \mathrm{Cl}$ & $p$ value \\
\hline \multicolumn{7}{|l|}{ Age } \\
\hline$\leq 60$ years & Reference & & & & & \\
\hline$>60$ years & 1.079 & $0.926-1.258$ & 0.329 & & & \\
\hline \multicolumn{7}{|c|}{ Marital status } \\
\hline Married & Reference & & & Reference & & \\
\hline Single & 0.740 & $0.620-0.882$ & 0.001 & 1.261 & $1.034-1.539$ & 0.022 \\
\hline DSW & 0.998 & $0.806-1.236$ & 0.984 & 1.238 & $1.035-1.479$ & 0.019 \\
\hline \multicolumn{7}{|l|}{ Primary site } \\
\hline upper third & Reference & & & & & \\
\hline middle third & 0.936 & $0.633-1.384$ & 0.740 & & & \\
\hline lower third & 0.798 & $0.554-1.150$ & 0.226 & & & \\
\hline overlapping & 1.081 & $0.727-1.607$ & 0.700 & & & \\
\hline \multicolumn{7}{|l|}{ Grade } \\
\hline I & Reference & & & & & \\
\hline II & 1.141 & $0.741-1.757$ & 0.549 & & & \\
\hline III & 1.481 & $0.973-2.253$ & 0.067 & & & \\
\hline IV & 1.112 & $0.614-2.012$ & 0.726 & & & \\
\hline \multicolumn{7}{|l|}{ Histology } \\
\hline ESCC & Reference & & & Reference & & \\
\hline EAC & 0.810 & $0.681-0.964$ & 0.018 & 0.808 & $0.674-0.969$ & 0.021 \\
\hline Others & 1.083 & $0.834-1.406$ & 0.549 & 1.113 & $0.853-1.454$ & 0.430 \\
\hline \multicolumn{7}{|l|}{ N stage } \\
\hline NO & Reference & & & & & \\
\hline N1 & 0.918 & $0.772-1.092$ & 0.334 & & & \\
\hline N2 & 0.929 & $0.697-1.237$ & 0.612 & & & \\
\hline N3 & 0.812 & $0.575-1.148$ & 0.238 & & & \\
\hline
\end{tabular}




\begin{tabular}{|c|c|c|c|c|c|c|}
\hline \multirow[t]{2}{*}{ Variables } & \multicolumn{3}{|c|}{ Univariate analysis } & \multicolumn{3}{|c|}{ Multivariate analysis } \\
\hline & Hazard ratio & $95 \% \mathrm{Cl}$ & $p$ value & Hazard ratio & $95 \% \mathrm{Cl}$ & $p$ value \\
\hline \multicolumn{7}{|c|}{ Chemotherapy } \\
\hline Done & Reference & & & Reference & & \\
\hline None & 3.256 & $2.777-3.817$ & $<0.001$ & 3.082 & $2.615-3.633$ & $<0.001$ \\
\hline \multicolumn{7}{|c|}{ Radiotherapy } \\
\hline Done & Reference & & & Reference & & \\
\hline None & 1.630 & $1.401-1.896$ & $<0.001$ & 1.305 & $1.111-1.534$ & 0.001 \\
\hline \multicolumn{7}{|l|}{ Surgery } \\
\hline Done & Reference & & & Reference & & \\
\hline None & 2.851 & $1.178-6.900$ & 0.020 & 2.865 & $1.175-6.988$ & 0.021 \\
\hline \multicolumn{7}{|c|}{ Brain metastasis } \\
\hline Yes & Reference & & & Reference & & \\
\hline NO & 0.642 & $0.487-0.848$ & 0.002 & 0.646 & $0.487-0.857$ & 0.223 \\
\hline \multicolumn{7}{|c|}{ Liver metastasis } \\
\hline Yes & Reference & & & Reference & & \\
\hline NO & 0.862 & $0.740-1.003$ & 0.055 & 0.828 & $0.708-0.969$ & 0.019 \\
\hline \multicolumn{7}{|c|}{ Lung metastasis } \\
\hline Yes & Reference & & & & & \\
\hline NO & 0.840 & $0.710-0.994$ & 0.042 & & & \\
\hline
\end{tabular}


Table 3

Univariate and multivariable Cox regression of CSS for analyzing the prognosis factors for primary esophageal cancer with bone metastases

\begin{tabular}{|c|c|c|c|c|c|c|}
\hline \multirow[t]{2}{*}{ Variables } & \multicolumn{3}{|c|}{ Univariate analysis } & \multicolumn{3}{|c|}{ Multivariate analysis } \\
\hline & Hazard ratio & $95 \% \mathrm{Cl}$ & $p$ value & Hazard ratio & $95 \% \mathrm{Cl}$ & $p$ value \\
\hline \multicolumn{7}{|l|}{ Age } \\
\hline$\leq 60$ years & Reference & & & & & \\
\hline$>60$ years & 1.074 & $0.919-1.256$ & 0.368 & & & \\
\hline \multicolumn{7}{|c|}{ Marital status } \\
\hline Married & Reference & & & Reference & & \\
\hline Single & 1.318 & $1.082-1.605$ & 0.006 & 1.228 & $1.002-1.506$ & 0.048 \\
\hline DSW & 1.357 & $1.134-1.623$ & 0.001 & 1.239 & $1.033-1.487$ & 0.021 \\
\hline \multicolumn{7}{|l|}{ Primary site } \\
\hline upper third & Reference & & & & & \\
\hline middle third & 0.886 & $0.598-1.313$ & 0.547 & & & \\
\hline lower third & 0.770 & $0.534-1.110$ & 0.162 & & & \\
\hline overlapping & 1.007 & $0.675-1.502$ & 0.972 & & & \\
\hline \multicolumn{7}{|l|}{ Grade } \\
\hline I & Reference & & & & & \\
\hline II & 0.822 & $0.448-1.507$ & 0.526 & & & \\
\hline III & 0.987 & $0.628-1.550$ & 0.955 & & & \\
\hline IV & 1.281 & $0.825-1.989$ & 0.270 & & & \\
\hline \multicolumn{7}{|l|}{ Histology } \\
\hline ESCC & Reference & & & Reference & & \\
\hline EAC & 0.802 & $0.672-0.958$ & 0.015 & 0.797 & $0.663-0.960$ & 0.017 \\
\hline Others & 1.100 & $0.844-1.434$ & 0.481 & 1.127 & $0.860-1.478$ & 0.385 \\
\hline \multicolumn{7}{|l|}{ N stage } \\
\hline NO & Reference & & & Reference & & \\
\hline N1 & 0.915 & $0.766-1.092$ & 0.325 & & & \\
\hline N2 & 0.890 & $0.661-1.198$ & 0.441 & & & \\
\hline N3 & 0.844 & $0.597-1.194$ & 0.338 & & & \\
\hline
\end{tabular}




\begin{tabular}{|c|c|c|c|c|c|c|}
\hline \multirow[t]{2}{*}{ Variables } & \multicolumn{3}{|c|}{ Univariate analysis } & \multicolumn{3}{|c|}{ Multivariate analysis } \\
\hline & Hazard ratio & $95 \% \mathrm{Cl}$ & $p$ value & Hazard ratio & $95 \% \mathrm{Cl}$ & $p$ value \\
\hline \multicolumn{7}{|c|}{ Chemotherapy } \\
\hline Done & Reference & & & Reference & & \\
\hline None & 3.220 & $2.737-3.788$ & $<0.001$ & 3.049 & $2.579-3.606$ & $<0.001$ \\
\hline \multicolumn{7}{|c|}{ Radiotherapy } \\
\hline Done & Reference & & & Reference & & \\
\hline None & 1.628 & $1.395-1.900$ & $<0.001$ & 1.305 & $1.106-1.539$ & 0.002 \\
\hline \multicolumn{7}{|l|}{ Surgery } \\
\hline Done & Reference & & & Reference & & \\
\hline None & 2.759 & $1.139-6.680$ & 0.025 & 2.784 & $1.140-6.796$ & 0.025 \\
\hline \multicolumn{7}{|c|}{ Brain metastasis } \\
\hline Yes & Reference & & & Reference & & \\
\hline NO & 0.648 & $0.487-0.863$ & 0.003 & 0.649 & $0.485-0.869$ & 0.004 \\
\hline \multicolumn{7}{|c|}{ Liver metastasis } \\
\hline Yes & Reference & & & Reference & & \\
\hline NO & 0.875 & $0.749-1.022$ & 0.092 & 0.841 & $0.716-0.987$ & 0.034 \\
\hline \multicolumn{7}{|c|}{ Lung metastasis } \\
\hline Yes & Reference & & & & & \\
\hline NO & 0.834 & $0.703-0.990$ & 0.039 & & & \\
\hline
\end{tabular}

Multivariate analysis further confirmed that marital status, histology, chemotherapy, radiotherapy, surgery and lung metastasis were independent prognostic factors for OS (all p<0.05, Table 2 ) and CSS (all $p<0.05$, Table 3). In details, patients receiving chemotherapy had a better prognosis than that who receiving nonchemotherapy (HR: $3.082,95 \% \mathrm{Cl}: 2.615-3.633, \mathrm{p}<0.001)$.

\section{Discussion}

Esophageal cancer is a highly lethal malignant tumor, approximately half of patients present with metastases to distant organs such as bone, liver, brain and lung at initial diagnosis ${ }^{15,16}$. The incidence rate of esophageal cancer with bone metastasis ranges from $5.2-8.0 \%$ in all stage patients ${ }^{6,17,18}$. Furthermore, OS was worst for bone metastases. To establish a comprehensive insight into whether chemotherapy is justifiably being prescribed to esophageal cancer patients with bone metastasis, we performed this retrospective study based 
on the SEER database. Our research found that chemotherapy was significantly associated with OS and CSS in esophageal cancer patients with bone metastasis. It meant that chemotherapy could reduce the risk of dying from all causes and reduce the risk of dying from esophageal cancer.

Previous studies have mentioned the effect of chemotherapy on survival in esophageal cancer with bone metastasis. Gerald et al. reported that most esophagogastric cancer patients, who underwent curative resections, have bone marrow micrometastases. They further found that a higher percentage of chemoradiotherapy patients were alive at 10 years $(28 \%)$ compared to surgery alone patients $(20 \%)$. It indicated a survival advantage with the chemoradiation strategy ${ }^{19,20}$. A retrospective study ${ }^{21}$ has investigated the clinical features and prognostic factors in esophageal cancer patients with bone metastasis. They found that higher serum CEA levels and no chemotherapy were significant risk factors for poor OS, indicating that bone metastasis patients may benefit from chemotherapy. A multicenter retrospective cohort study suggested that among patients with recurrent or metastatic esophageal squamous cell carcinoma who cannot tolerate or whose tumors are refractory to fluorouracil, platinum and taxane, those receiving active salvage chemotherapy achieved better OS than those receiving best supportive care ${ }^{22}$. Consistent with the previous results, our univariate analysis suggests that the non-chemotherapy showed a poorer prognosis than the chemotherapy. In addition, adjusting for clinical and treatment variables, chemotherapy was also an independent prognostic factor for esophageal cancer patients with bone metastasis. Compared to patients who received chemotherapy, the hazard ratios for patients who didn't receive chemotherapy was 3.082(95\% Cl: 2.6153.633).

Our research further explores the association between chemotherapy and survival by stratifying patients by tumor grade and histological subtype. Both in squamous cell carcinoma or adenocarcinoma subgroups, chemotherapy could significantly improve OS and CSS. Chemotherapy was a good prognostic indicator for OS and CSS in both squamous cell carcinoma and adenocarcinoma patients. In patients with grade I esophageal cancer, neither OS nor CSS were significant between the chemotherapy and non-chemotherapy groups. This result means that chemotherapy may not improve the prognosis of grade I esophageal cancer. To date, no common consensus that the necessity of chemotherapy is used for grade I esophageal cancer with bone metastasis has established. Considering the balance of the survival outcomes and the toxicity, chemotherapy is not recommended for grade I esophageal cancer patients. However, due to the small sample size of grade I patients, more prospective and retrospective studies need to be conducted to confirm our results.

Combination chemotherapy consisting of 5-fluorouracil plus cisplatin was recommended to recurrent or metastatic esophageal cancer, but the overall response rate of the included patients was $33.3 \%{ }^{23}$. As the low response rate of chemotherapy and poor prognosis of esophageal cancer, patients with distant organ metastasis also suggest being treated with a multidisciplinary approach, using modalities such as radiotherapy, surgery and various medical treatments that include chemotherapy, hormone therapy, and bonemodifying agents ${ }^{21,24,25}$. Tanaka et al. evaluated the role of multimodality therapy in esophageal squamous cell cancer patients with distant organ metastasis. They found that multimodality therapy, which included chemoradiotherapy, surgery followed by chemotherapy and/or radiation therapy, could improve survival of the esophageal squamous cell cancer patients with distant organ metastasis ${ }^{11}$. On the basis of the encouraging result, the finding further underscores the need for chemotherapy approaches in this disease.

Page $13 / 20$ 
Patients with bone metastases had significantly poorer OS than those with metastasis to other sites. ${ }^{6}$ Therefore, to have a more prolonged OS and improved quality of life are the idea expectation for the end-stage cancer patients whose life expectancy is short. ${ }^{26,27}$ chemotherapy is the first-line therapy for esophageal cancer with distant metastases ${ }^{12,28}$. Nevertheless, a standard first-line treatment for bone metastases has not yet been established. To determine whether all esophageal cancer patients with bone metastasis should undergo chemotherapy, we conducted this study using the SEER database. To our knowledge, this research is the first comprehensive, population-based study evaluating the efficacy of chemotherapy for esophageal cancer with bone metastasis.

In order to minimize the baseline discrepancies and increase the comparability, we conducted 1:1 chemotherapy: the non-chemotherapy PSM analysis. PSM is an analysis of an even distribution of confounders between groups, and there is a tendency for observational studies applied this statistical method because of its advantages ${ }^{29}$. By performing PSM analysis, we further validated that esophageal cancer with bone metastasis patients undergoing chemotherapy has a promising prognosis with high credibility.

Nevertheless, there were some limitations in the present study. First, detailed information about chemotherapy such as regimens, doses and duration were missing from the database. Consequently, a further conclusion could not be drawn due to insufficient information. Second, since all the dataset was collected from retrospective studies and no randomization of treatment cohorts. It may lead to reporting bias and selection bias. Thirdly, the efficacy of the chemotherapy was evaluated by the OS and CSS in this study. Side effects, cost-effectiveness and performance status, could be included as evaluations in the future study to assess patient status comprehensively.

In conclusion, this study suggested that chemotherapy significantly improved OS and CSS in esophageal cancer patients with bone metastasis, chemotherapy was an independent prognostic factor for esophageal cancer patients with bone metastasis. However, chemotherapy might not improve the prognosis of grade I esophageal cancer. Furthermore, more prospective studies need to be conducted to confirm our results. Despite several limitations, the results ought to provide severe consideration when making a treatment decision for esophageal cancer patients with bone metastasis.

\section{Declarations}

\section{CONFLICT OF INTEREST}

The authors declare that there is no conflict of interest.

\section{FUNDING}

None.

\section{References}

1. Hur, C. et al. Trends in esophageal adenocarcinoma incidence and mortality., 119, 1149-1158 (2013).

2. Siegel, R. L., Miller, K. D. \& Jemal, A. J. Cancer statistics, 2019. CA Cancer J Clin, 69, 7-34 (2019). 
3. Smyth, E. C. et al. Oesophageal cancer. Nat Rev Dis Primers, 3, 1-21 (2017).

4. Pennathur, A. et al. Oesophageal carcinoma., 381, 400-412 (2013).

5. Domper Arnal, M. J., Ferrández Arenas, Ã. \& Lanas Arbeloa, Ã. Esophageal cancer: Risk factors, screening and endoscopic treatment in Western and Eastern countries. World J Gastroenterol, 21, 7933-7943 (2015).

6. Wu, S. G. et al. Sites of metastasis and overall survival in esophageal cancer: a population-based study. Cancer Manag Res, 9, 781-788 (2017).

7. Imura, Y. et al. Clinical features and prognostic factors in patients with esophageal cancer with bone metastasis. Oncol Lett, 19, 717-724 (2020).

8. Berenson, J. R. et al. Zoledronic acid reduces skeletal-related events in patients with osteolytic metastases., 91, 1191-1200 (2001).

9. Wu, S. G. et al. Surgery Combined with Radiotherapy Improved Survival in Metastatic Esophageal Cancer in a Surveillance Epidemiology and End Results Population-based Study. Sci Rep, 6, 28280 (2016).

10. Kamangar, F. et al. The global, regional, and national burden of oesophageal cancer and its attributable risk factors in 195 countries and territories, 1990-2017: a systematic analysis for the Global Burden of Disease Study 2017. Lancet Gastroenterol Hepatol, 5, 582-597 (2020).

11. Tanaka, T. et al. Outcomes of multimodality therapy for stage IVB esophageal cancer with distant organ metastasis (M1-Org). Dis Esophagus, 23, 646-651 (2010).

12. Ajani, J. A. et al. Esophageal and Esophagogastric Junction Cancers, Version 2.2019, NCCN Clinical Practice Guidelines in Oncology. J Natl Compr Canc Netw, 17, 855-883 (2019).

13. Cunningham, D. et al. Perioperative chemotherapy versus surgery alone for resectable gastroesophageal cancer. N Engl J Med, 355, 11-20 (2006).

14. Klevebro, F. et al. A randomized clinical trial of neoadjuvant chemotherapy versus neoadjuvant chemoradiotherapy for cancer of the oesophagus or gastro-oesophageal junction. Ann Oncol, 27, 660667 (2016).

15. Enzinger, P. C. \& Mayer, R. J. Esophageal cancer. N Engl J Med, 349, 2241-2252 (2003).

16. Horner, M. J. et al. SEER Cancer Statistics Review, 1975-2006. Bethesda, MD: National Cancer Institute; 2009. Available from: http://seer.cancer.gov/csr/1975_2006/. Accessed May 10, 2017.

17. Ai, D. et al. Patterns of distant organ metastases in esophageal cancer: a population-based study. $J$ Thorac Dis, 9, 3023-3030 (2017).

18. Wu, S. G. et al. Patterns of Distant Metastasis Between Histological Types in Esophageal Cancer. Front Oncol, 8, 302 (2018).

19. O'Sullivan, G. C. et al. Micrometastases in esophagogastric cancer: high detection rate in resected rib segments., 116, 543-548 (1999).

20. Ryan, P. et al. Prognostic significance of prospectively detected bone marrow micrometastases in esophagogastric cancer: 10-year follow-up confirms prognostic significance. Cancer Med, 4, 1281-1288 (2015).

21. Imura, Y. et al. Clinical features and prognostic factors in patients with esophageal cancer with bone metastasis. Oncol Lett, 19, 717-724 (2020). 
22. Nomura, M. et al. Active salvage chemotherapy versus best supportive care for patients with recurrent or metastatic squamous cell carcinoma of the esophagus refractory or intolerable to fluorouracil, platinum, and taxane. Cancer Chemother Pharmacol, 78, 1209-1216 (2016).

23. Hayashi, K. et al. Phase II evaluation of protracted infusion of cisplatin and 5-fluorouracil in advanced squamous cell carcinoma of the esophagus: a Japan Esophageal Oncology Group (JEOG) Trial (JCOG9407). Jpn J Clin Oncol, 31, 419-423 (2001).

24. Xi, M. et al. The impact of histology on recurrence patterns in esophageal cancer treated with definitive chemoradiotherapy. Radiother Oncol, 124, 318-324 (2017).

25. Merz, V. et al. A phase II trial of the FGFR inhibitor pemigatinib in patients with metastatic esophagealgastric junction/gastric cancer trastuzumab resistant: the FiGhTeR trial. Ther Adv Med Oncol, 12, 1758835920937889 (2020).

26. Simmonds, P. C. Palliative chemotherapy for advanced colorectal cancer: systematic review and metaanalysis. Colorectal Cancer Collaborative Group. BMJ, 321, 531-535 (2000).

27. Liu, Y. et al. Clinical benefits of combined chemotherapy with S-1, oxaliplatin, and docetaxel in advanced gastric cancer patients with palliative surgery. Onco Targets Ther, 9, 1269-1273 (2016).

28. Sun, S. et al. Phase II Study of S-1 plus Cisplatin as First-Line Therapy in Patients with Metastatic Esophageal Carcinoma. Oncol Res Treat, 42, 115-122 (2019).

29. Baek, S. et al. Propensity score matching: a conceptual review for radiology researchers. Korean J Radiol, 16, 286-296 (2015).

\section{Figures}




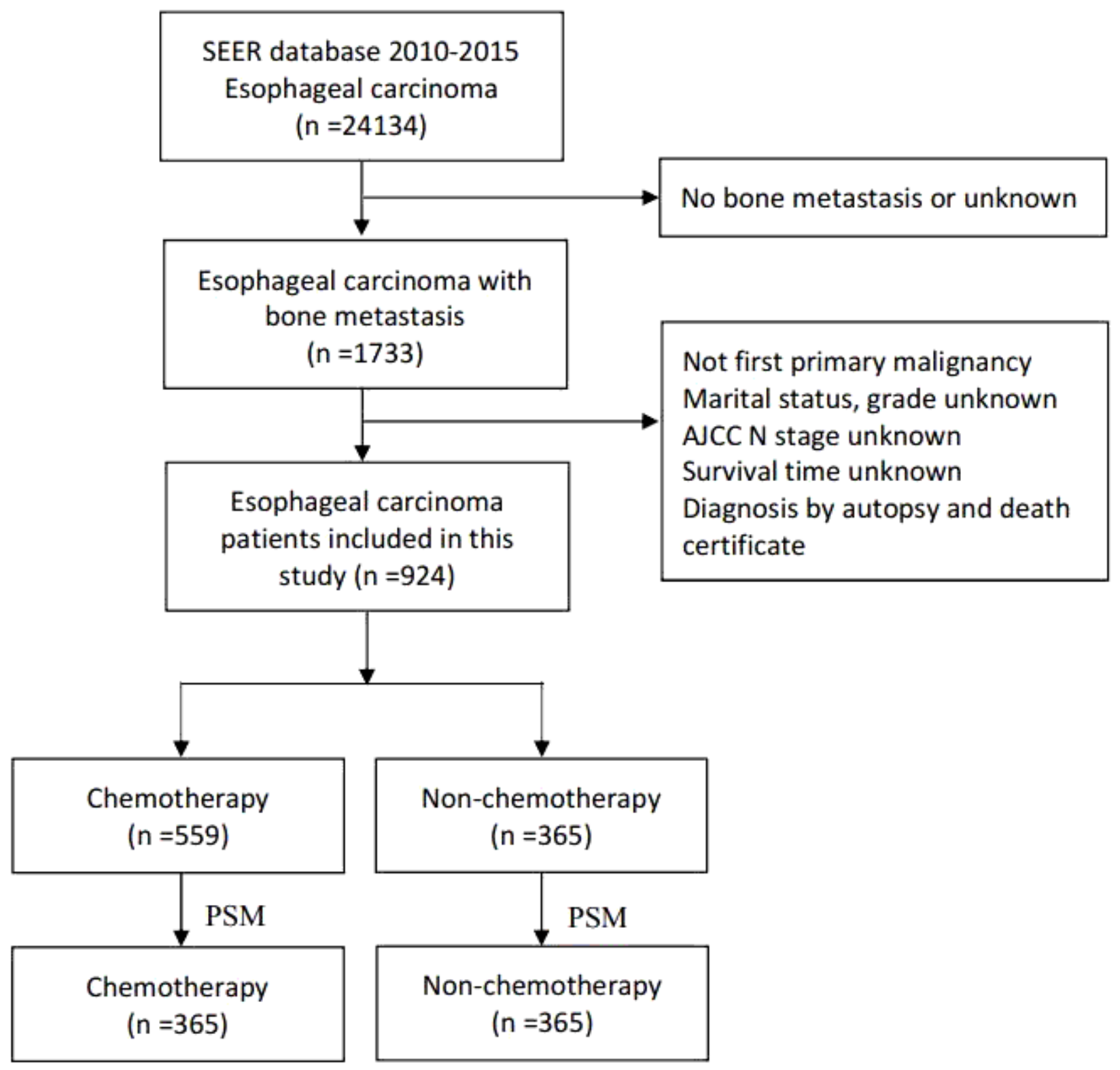

Figure 1

Study flowchart for esophageal cancer patients' inclusion and exclusion. 

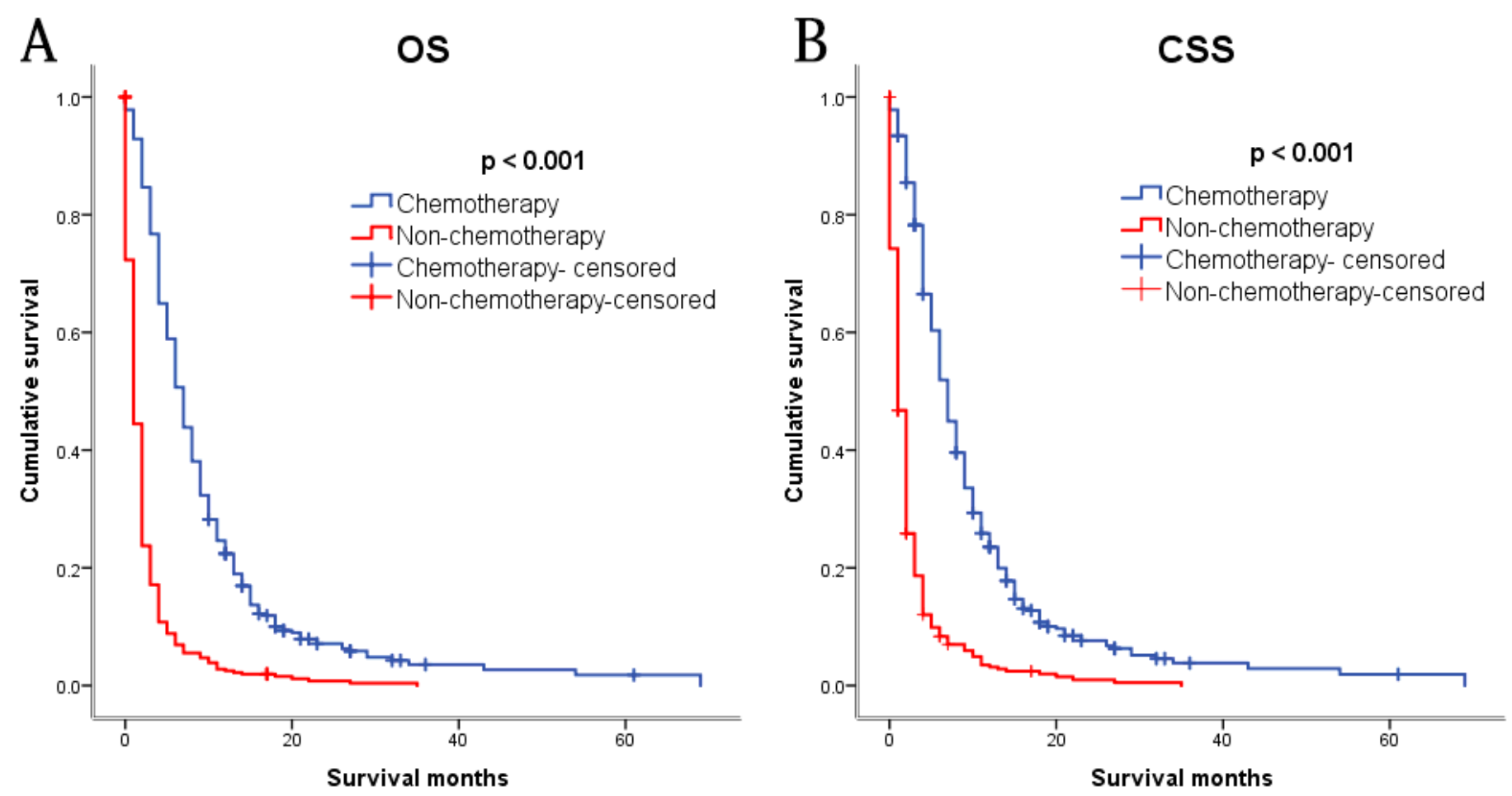

\section{Figure 2}

Kaplan-Meier survival curves of the effect of chemotherapy and non-chemotherapy OS, overall survival; CSS, cancer-specific survival. 

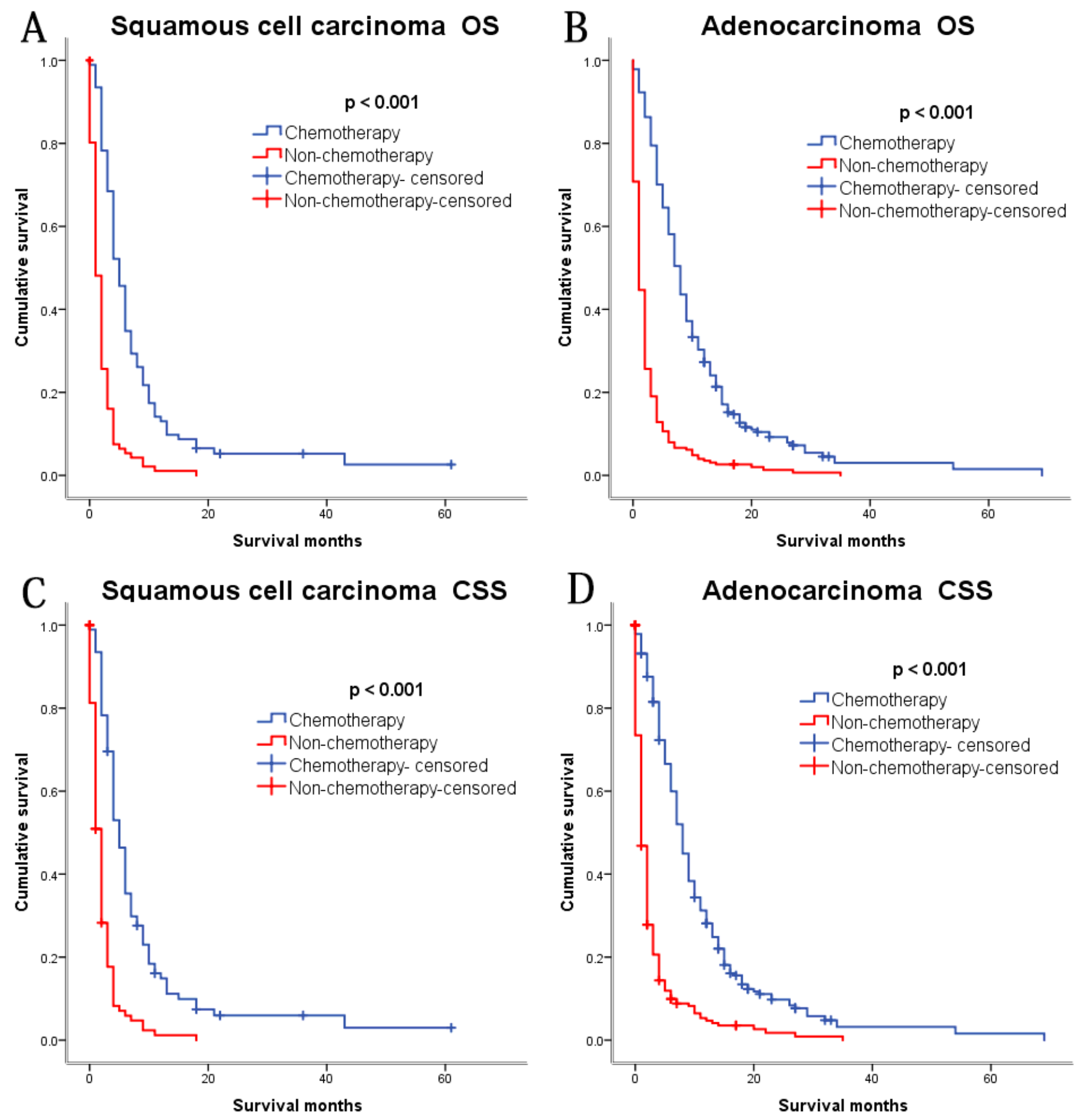

Figure 3

Kaplan-Meier survival curves of the effect of chemotherapy on OS (A, B) and CSS(C, D) by squamous cell carcinoma or adenocarcinoma. OS, overall survival; CSS, cancer-specific survival. 

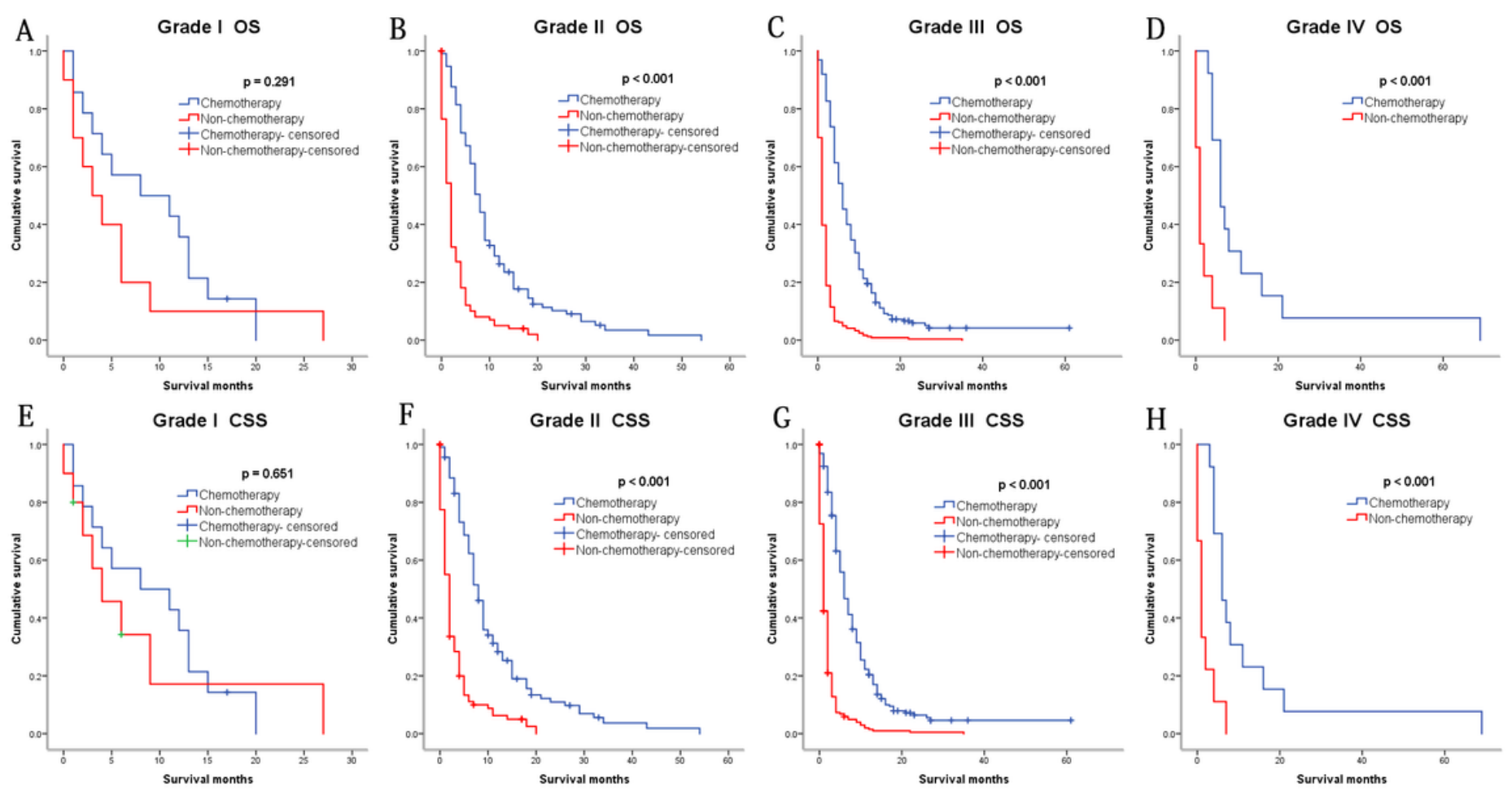

\section{Figure 4}

Kaplan-Meier survival curves of the effect of chemotherapy on OS (A-D) and CSS (E-H) tumour grade. OS, overall survival; CSS, cancer-specific survival. 